\title{
The Impacts of Technical Employees' Departure on Historic Buildings Organizations' Performance
}

\author{
Salem Mokhtar Tarhuni \\ Department of Interior Architecture and Environmental Design, Faculty of Architecture, Bursa Orhangazi University, Turkey
}

Copyright $\mathrm{C} 2016$ by authors, all rights reserved. Authors agree that this article remains permanently open access under the terms of the Creative Commons Attribution License 4.0 International License

\begin{abstract}
Historic buildings (HBs) regarded as a national heritage for the countries and should therefore be maintained. Most governments have established institutions to conserve HBs. The Management of Historical Cities Bureau (MHCB) is a governmental non-profit institution has established since 1986 in Tripoli - Libya. This institution suffers from departure of senior technical staff. The objectives of this paper are to explore the rate of technical employees' movement and its impacts on the performance of MHCB and the reasons that make them leave. Also, it shed light on knowledge management (KM) efforts for recovering intellectual capital in the MHCB. Multi-methods were used for collecting data: analysing organisational documents, interviews, and observations that included taking notes and pictures. The findings presented that a high rate of technical staff left the MHCB between 1990 and 2010. This situation impacted the performance of the MHCB in terms of repetition of mistakes in repairing $\mathrm{HBs}$ due to a knowledge gap in the MHCB. This also, caused non-continuity of knowledge transfer and damage to accumulated knowledge, in addition to the cost of the time and money for rehabilitating technical staff. The significant hidden threat to Libyan HBs is most of departing staff will not use their knowledge in the field of HBs conservation. The chance for departing technical staff to get a job in the same field in other organization is very few. Also, the leaving of technical staff is irreplaceable because this institution is unique in Tripoli. The opportunity of specialist transition from other organization to MHCB is very few. The main reasons why employees leave the institution are: administrative changes, disagreement between employees and their heads and limited motivations combined with unhealthy and dangerous workplaces in old buildings. Finally, the paper shed light on knowledge management (KM) efforts that can recover some intellectual capital in the MHCB.
\end{abstract}

Keywords Historic Buildings (HBs), HBs Conservation Institutions, Technical Employees' Movement, Knowledge management, Tripoli-Libya

\section{Introduction}

Historic buildings (HBs) are old buildings, adopted with new and changeable function, located in or outside the zone of neighborhoods or historic cities. Mostly, have some architectural, historic, economic, environmental and social values. They are regarded as a national heritage for the countries and should therefore be maintained. Most governments have established institutions to conserve HBs. The Management of Historical Cities Bureau (MHCB) is a governmental non-profit institution has established since 1986 in Tripoli - Libya. The mission of the MHCB is the conservation of HBs in the city of Tripoli. However, this institution has been suffering from departure of senior technical employees.

The objectives of this paper are to explore the rate of technical employees' movement and its impacts on the MHCB and the reasons that make them leave.

The paper includes the advantages of technical employees' retention, the impacts of their departure in the performance of $\mathrm{MHCB}$ and, the reasons of their leaving. Also, it sheds light on the role of $\mathrm{KM}$ on recovering some intellectual capital in the MHCB.

\section{The Advantages of Staff Retention}

Individuals in terms of employees or specialists are the main knowledge source in the organisational context. They are considered as a store of tacit knowledge. Tsoukas [1] stated that "individual human agents have their own unique mental representation of the world." Also, Rowley [2] stated that "Knowledge resides with individuals and may largely derive from experience."

In the field of HBs conservation, Consortium [3] tends to consider professional architects and civil engineers acquired HBs conservation knowledge as he stated:

"Normally, it is the professional architect and/or structural/civil engineer specialized in conservation-restoration who acquires these knowledge, skills and competencies to become what has often been termed the conservation architect". 
However, 'staying in the same job' ensures employees get knowledge from accumulated experiences. This leads to performing the work efficiently. Regarding historic buildings conservation, the expert in this field 'Fielden' [4] stated that "staff retention is an important factor in staff developing a thorough knowledge". In addition to achieving the scope of work, senior technical employees contribute to transfer technical and management knowledge to junior architects, engineers, technicians, surveyors and draftsmen. They enrich the discussions that increase knowledge sharing.

\section{Methodology}

The objectives of this paper are to explore the rate of technical employees' movement and its impacts on the performance of MHCB in conserving Libyan historic buildings. Also, it explored the reasons that were combined in the MHCB to make technical staff leave, and shed light on $\mathrm{KM}$ efforts that can help recovering some intellectual capital in the MHCB. The field research was conducted in Tripoli, Libya between 20/9/2010 and 30/11/2010. However, there is a difficulty to up-date the data because of the situation in Libya. Multi-methods were used for collecting data and information: analysing administration records and, interviews with current and previous employees in addition to observations (taking notes and pictures).

The administration records of technical employees in the MHCB between 1986 and 2010 were analyzed in order to find the rate of technical staff who left the MHCB between 1986 and 2010. The names and dates of current and previous technical employees, who had worked in the MHCB since 1986, were collected and reviewed with some existing and previous senior employees (during interviews) to make sure that no names were missed.

Furthermore, semi-structured interviews were conducted with twelve interviewees representing various parties in the MHCB and local HB conservation field. The frame for choosing the interviewees who agreed to an interview included: the interviewee having experience of ten years or more in the field of HBs conservation and knowing about the MHCB and local HB conservation work.
Also, the selection process considered the variation of levels to better reflect opinion regarding the existing situation in this institution. The chosen employees were asked to name previous technical employees in the field of HB conservation. However, the respondent interviewees' experience ranged between ten and twenty five years, with $66.7 \%$ of them $(8 / 12)$ being MHCB key employees: top level management (two interviewees), medium level management (three interviewees), and other senior technical employees (three interviewees). The rest were four interviewees from outside the MHCB, representing 33.3\% of interviewees (4/12); three were previously technical employees at the MHCB, and the coordinator of the national group for protecting $\mathrm{HBs}$ who has cooperated with the MHCB.

The interviewees group was comprised of: five architects, two civil engineers, three technicians, one librarian and one fine artist.

\section{The Findings}

\subsection{Statistics about Technical Staff and Their Movement in the MHCB}

The current technical staff in the MHCB numbered 30 employees; 4 architects, 3 civil engineers, 6 technicians and the remaining 17 members of technical staff are surveyors and draftsmen. However, the administration records that include previous technical employees were analysed in order to find the rate of their leaving the MHCB between 1986 and 2010.

The comprehensive view (table 1 and figure 1) shows that the total number of technical employees who left the MHCB between 1986 and 2010 was 56, including 25 architects, 17 civil engineers and 14 surveyors/draftsmen. The percentage of total technical staff leaving was $65.12 \%$. The most significant rate of departure was among architects $(86.20 \%)$ and civil engineers (85\%), compared with surveyors and draftsmen at $45.16 \%$. No technicians left the MHCB.

Table 1. The number of MHCB's technical employees between 1986 and 2010

\begin{tabular}{|c|c|c|c|c|c|}
\hline $\begin{array}{c}\text { Duration of working in } \\
\text { MHCB }\end{array}$ & Architects & $\begin{array}{c}\text { Civil } \\
\text { Engineers }\end{array}$ & Technicians & $\begin{array}{c}\text { Surveyors+ } \\
\text { draftsmen }\end{array}$ & Total \\
\hline $1986-2010$ (all) & 29 & 20 & 6 & 31 & 86 \\
\hline 2010 (existing) & 4 & 3 & 6 & 17 & 30 \\
\hline Number of departures & 25 & 17 & - & 14 & 56 \\
\hline percentage of leaving & $(25 / 29) 86.20 \%$ & $(17 / 20) 85 \%$ & $0 \%$ & $(14 / 31) 45.16 \%$ & $(56 / 86) 65.12 \%$ \\
\hline
\end{tabular}




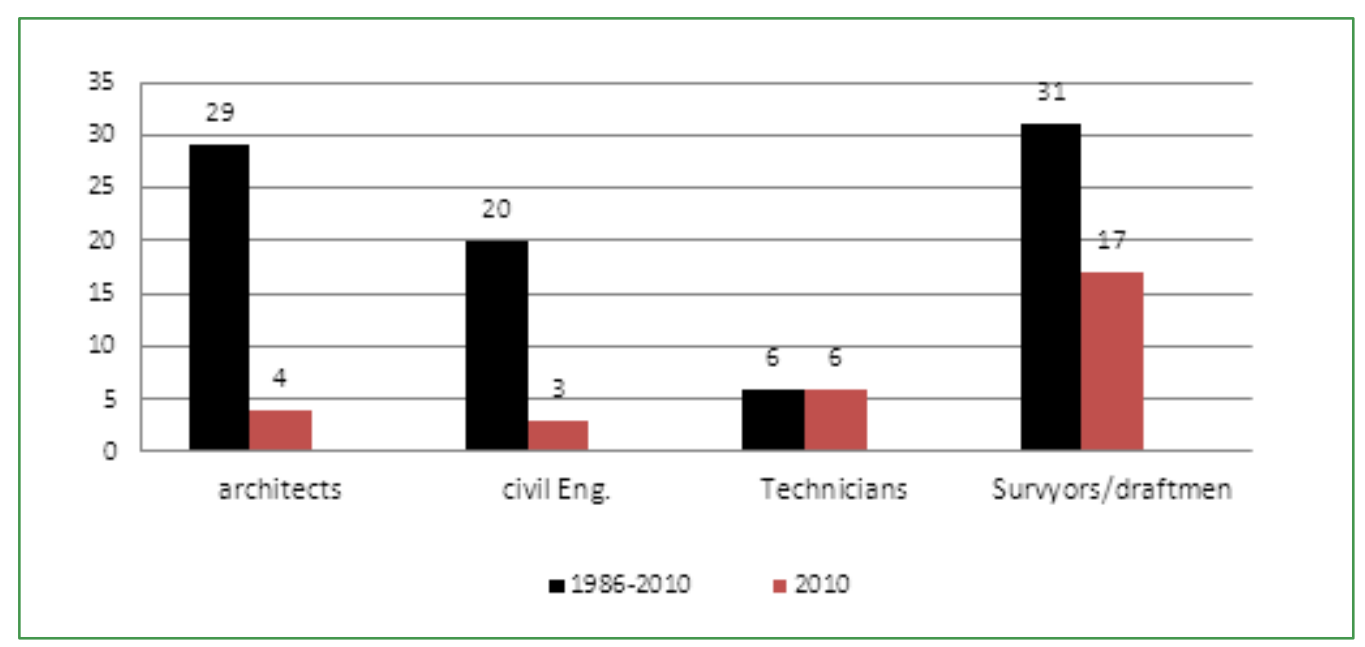

Figure 1. A comparison between the number of existing technical employees (2010) and total number of technical employees who worked in the MHCB between 1986 and 2010

In more details, figure 2 shows that the highest number of architects who had worked in the MHCB was between 1990 and 1994 (12 architects). The number decreased later and fluctuated between four and seven in the duration between 1999 and 2010. Also, the highest number of civil engineers was in 1992 (11 engineers). The number decreased later and fluctuated between three and five in the duration between 1999 and 2010. However, the maximum number of surveyors and draftsmen was 23 in 1993 and the number continued to be stable between 17 and 20 in the duration between 1999 and 2010. The number of technicians remained stable (six) from 2004 to 2010.

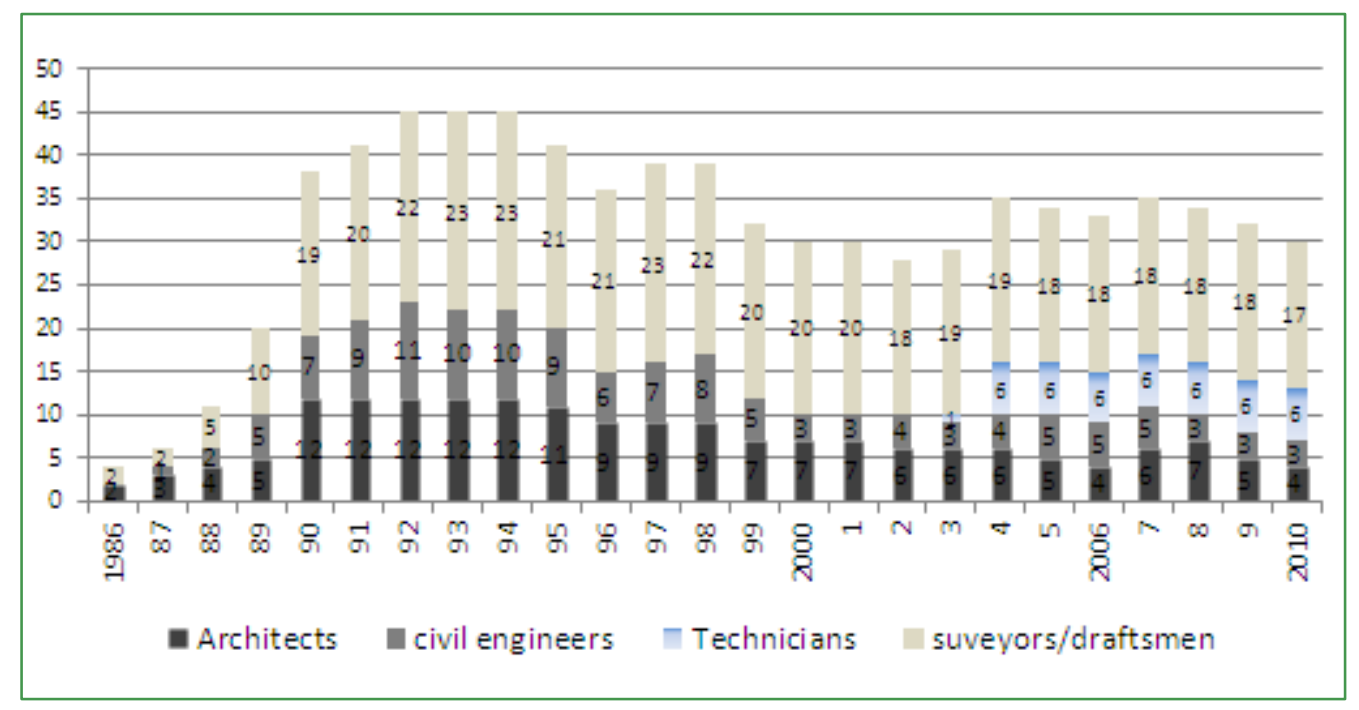

Figure 2. Number of technical employees in the MHCB between 1986 and 2010

This fluctuation of technical staff numbers reflects the range of their movement in the MHCB. Figure 3 illustrates the numbers of technical employees who left the MHCB between 1990 and 2010. 


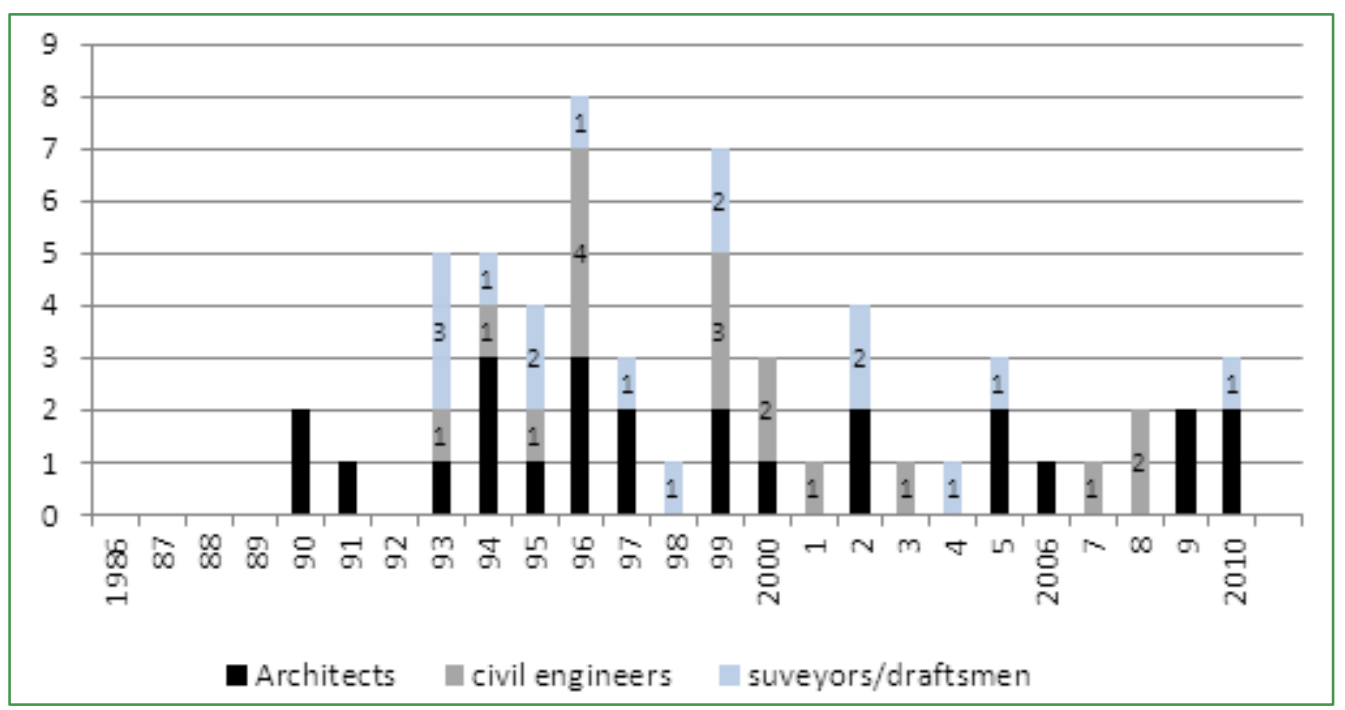

Figure 3. Number of technical employees who left the MHCB between 1986 and 2010

Table 2. The work experience for technical employees who left the MHCB between 1990 and 2010

\begin{tabular}{|c|c|c|c|c|c|}
\hline Technical staff & Architects & Civil engineers & Technicians & Surveyors/draftsmen & Total \\
\hline $\begin{array}{c}\text { Number of departing } \\
\text { employees }\end{array}$ & 25 & 17 & - & 14 & \\
\hline Range (min - max) & $2-19$ years & $2-19$ years & - & $2-20$ years & $\begin{array}{c}2-20 \\
\text { years }\end{array}$ \\
\hline Mean of work years & 6.3 years & 6.05 years & - & 7.28 years & 6.5 years \\
\hline
\end{tabular}

The average of work experience for the technical employees who left the MHCB between 1990 and 2010 was 6.5 years (table 2), and the range was between two and twenty years. However, 12 architects, 7 civil engineers and 10 surveyors left after more than 5 years of work experience in the MHCB.

\subsection{The Interviews and Observations about the Impacts and the Reasons of Employees' Movement}

On this theme, information regarding the impacts and reasons of technical employees' departure were collected from interviews with twelve interviewees representing various parties in the MHCB and previous senior employees in the MHCB.

Regarding the impacts of employees' movement, generally, all interviewees agreed about the existence of this problem in the MHCB. A senior technical employee stated: "Unlike other departments, technical department staff are the most changeable staff." Also, the director of the MHCB library stated that "A group of senior employees and consultants have left this institution. It was a loss for the institution, an irreplaceable loss." Furthermore, all interviewees agreed regarding the negative effects of this action. Most of them emphasized that it affected the MHCB performance and had caused a knowledge gap or leakage and non-continuity of knowledge transfer, in addition to being a waste of time and costing money for rehabilitating technical staff and for dealing with external consultant offices.

The high rate of departure of architects and engineers has negatively affected the MHCB performance. The head of the architectural studies section argued that all senior architects and engineers are busy on multiple tasks and unqualified juniors became decision makers in some cases. However, this situation caused repetition of mistakes and delay of conservation work. The main repeated mistakes that were observed in refurbished HBs under supervision of the MHCB include: removing all old plaster layers, using cement mortar for plastering, using reinforced concrete for treating cracks, and using inappropriate metal ties for supporting arches. One example is the former Bank of Rome in the old city of Tripoli, Libya (figure 4). Although the refurbishment works were conducted in 2004, it was done in the wrong way due to removing all old plaster layers and use Portland cement for re-plastering. This wrong intervention in HBs led to high dampness in walls. 

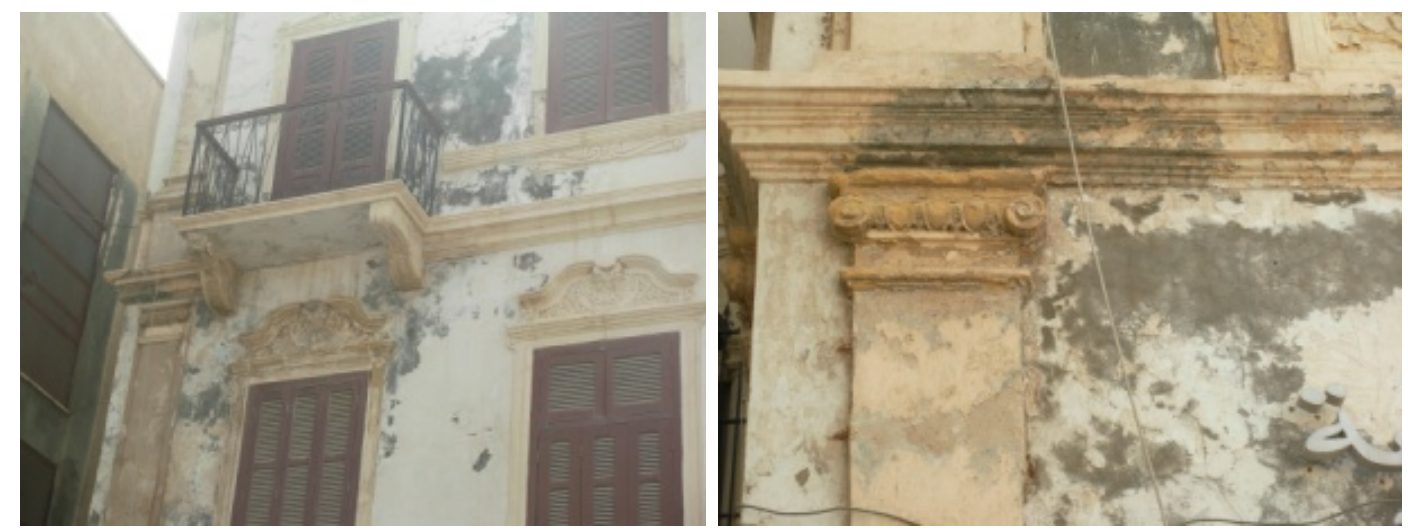

Figure 4. High dampness in the walls of former Bank of Rome, Tripoli

Furthermore, at the top level management, the head of the institution stated that "the lack of experts due to senior staff leaving forced the MHCB to depend on external consultants and consultancy offices (short contract) for conducting some HB conservation studies." This means extra cost and extra time for performing the work.

Regarding knowledge gap and non-continuity of knowledge transfer, the head of technical studies stated that "Architects and others who left the MHCB have caused a knowledge gap, because we have lost their knowledge." Also, an ex-senior cooperative engineer at the MHCB stated "the departure of employees from the bureau has led to the loss of the knowledge that they possess, in addition to the cost of the time and money for habilitating them." Furthermore, an exsenior architect mentioned that "seniors have left the institution; most knowledge that employees have is in their minds, and unfortunately it leaves when the holder leaves the institution." Moreover, an ex-architect stated that "senior architects and engineers who have left the institution have caused the non-continuity of knowledge transfer in this institution; it has caused a type of damage to accumulated knowledge". Finally, an engineer mentioned the loss of explicit knowledge, as he claimed that "some studies and reports which had already been done by employees who have left the MHCB were lost because only they know where they are".

Previous quotations present a problem as technical employees had left the MHCB with the knowledge that they had built from years of work experience in the field of HB conservation. This situation presents a threat against HB conservation. The MHCB cannot meet its objectives of conserving HBs effectively due to a knowledge gap. There is non-continuity of knowledge transfer and leakage of knowledge they have in their minds and also explicit knowledge may they have or have access to. This caused repeating the repairing work because of mistakes, in addition to being a waste of time and costing money to repeat the work, to habilitate technical staff, and to deal with external consultants and consultancy offices.

Regarding the reasons of employees' movement, three interviewees attributed this to the administrative changes. An ex- architect stated about the results of the administration changes that "The heads of this institution have been changed more than seven times since its establishment. When the head manager leaves some architects and engineers depart this institution too. Others leave because they disagree with their heads." Other two interviewees attributed that to the lack of organisation policies regarding staff motivation, as an ex-architectural employee stated that "although the work type is harder than normal jobs there is not enough motivation provided for technical employees." Moreover, a senior technical employee stated that "although of unhealthy and dangerous work places in old buildings, there are fixed salaries and limited motivations for technical staff to continue in this institution." This is true as observed in the old city of Tripoli (figure 5).

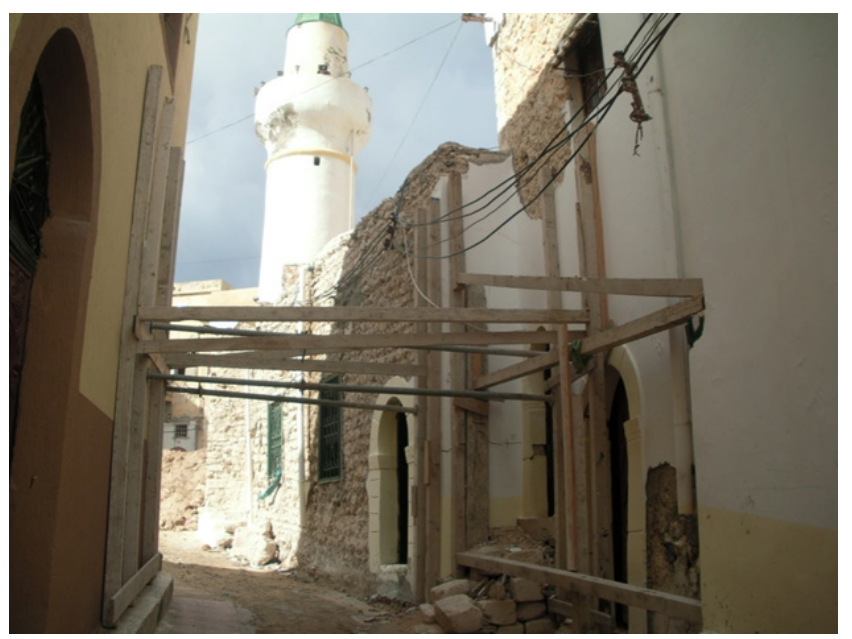

Figure 5. Jama Mushat Tripoli - an example of dangerous workplaces in old buildings (the author 2010)

In brief, the main reasons why employees leave the institution are: administrative changes, disagreement with their heads and, limited motivations combined with unhealthy and dangerous workplaces in old buildings.

\section{Discussions}

Statistics of technical employees illustrate that the percentage of total technical staff that had left the MHCB 
between 1986 and 2010 was $65.12 \%$. The architects and civil engineers were the most frequently changed staff. The statistics (table 1, figure 1) illustrated that $85 \%$ of architects and civil engineers left the MHCB, whereas $38 \%$ were left among surveyors and draftsmen.

The point here is that architects, engineers, surveyors and draftsmen have left this institution with the knowledge they gained from years of work (practical) experience in the field of HB conservation. This situation is considered a threat against conserving $\mathrm{HBs}$ in the MHCB. However, staff leaving with their knowledge is known in the literature. For instance, Egbu et al [5] stated that:

"It seems that the importance of the employees' knowledge is often realized, perhaps too late, when the employee is about to leave the organization, as he/she prepares to take with him/her knowledge and experience gained over the years".

Furthermore, Sheehan et al [6] stated that "senior staff retires or leave organisations regularly, potentially taking tacit knowledge and potential source of competitive advantage with them".

In the MHCB, the interviews' findings (section 4.2) showed that because of the huge technical staff turnover, MHCB cannot meet its objectives of conserving HBs effectively. The senior architects and engineers with work experience were replaced by unqualified juniors who became decision makers. A lack of experts within the MHCB who could conduct conservation work correctly caused repetition of mistakes (figure 4) that delays and increases the cost and time for performing repairing work. Also, the institution has wasted both, the time and money that was spent on developing departing technical employees' skills and knowledge.

The continued departure of technical staff had caused also, a knowledge gap and non-continuity of knowledge transfer. The institution has lost not only their personal knowledge but also the explicit knowledge they may have or have access to. Most seniors have left the MHCB, without transferring their knowledge to juniors. In this regard, Macintosh [7] stated that "there are trends for employees to retire earlier and for increasing mobility, leading to loss of knowledge". However, in comparison with other businesses, (relatively) the loss of any senior technical staff member from a HB conservation organisation is an irreparable loss. This is because the number of specialists in the field of HB conservation is limited, particularly in Libya. The departing senior architects and engineers are irreplaceable due to the MHCB being the only governmental institution responsible for conserving HBs in the city of Tripoli. This means the opportunity of employees with sufficient experience transition from other similar organizations in the country is very few. Moreover, the significant hidden threat to Libyan HBs is most of departing staff will not use their knowledge in the field of HBs conservation. The field of new design and construction attract them. The chance for departing technical staff to get a job and use their knowledge in the field of HBs conservation is very few because this institution is unique in Tripoli.

The reasons as discussed in section 4.2 that were combined in the MHCB to make technical staff leave include: the administrative changes, disagreements between technical employees and their heads, and insufficient motivation policies, in addition to the fact that the work type is special and harder than normal jobs in terms of dangerous work places in the old HBs restoration projects (figure 5). Although retirement appears in literature as a main reason for leaving the work, no cases of retirement were observed in the MHCB, all departing technical staff still under the age of retirement. The situation of employees' departure has been considered in the wider literature in the field of knowledge management.

Knowledge management $(\mathrm{KM})^{1}$ can help recover some intellectual capital in organisations. The situation in the MHCB calls to provide sufficient policies that motivate technical staff to stay. One of KM's goals is to ensure that knowledge-workers stay with the company through staff motivation policies (Beijerse [8]). Furthermore, KM processes include knowledge developing, capturing and sharing, Rowley [9], and Murthy and Panchal [10] state that developing organizational norms and values which support the creation and sharing of knowledge is essential for successful organizations. Other KM norms or policies have been mentioned by Vector [11], such as incorporating rewards into performance measurement plans and making content submission mandatory. The literature in the field of KM mentioned that to understand the hidden meaning, a rich data context in studies and reports is essential in the articulation process, as Brandon et al [12] stated:

"Since people always shuffle within and between companies, it is difficult to reach the historical report authors who understand the hidden meaning of project historical data. The historical data should provide a rich data context so that it can be used with minimum or no consultation of authors".

On the other hand, Bishop [14] stated that KM activities should be seen as a useful aspect of work rather than something that is required and, therefore, the policies and procedures approach should be minimized. Also, Rowley [15] stated that:

"Knowledge resides with individuals and may largely derive from experience. This embedded knowledge will only be drawn out if those individuals reflect on, and are convinced by, the fact that they need to share their knowledge."

Finally, the scholars in the field of HB conservation, Dann and Wood [16] call for appropriate outsourcing policies to ensure that the organization has the required skills available. One of external sources of knowledge is individuals who left

1 Knowledge management (KM) can be defined as: "the management processes that enable organisations to identify available and required knowledge, capture and share it for effective use to achieve organisational objectives and create new knowledge (Tarhuni [13])". 
their organizations after years of accumulated experiences.

Individuals who retired or left the MHCB after significant years of practical experience are still available but needs accessible. There is an opportunity to benefit from them, particularly those who are still interested in HBs and their conservation and have a willingness to share their knowledge in 'for instance' mentoring juniors, providing lectures and training courses. However, the organization has to know those knowledge holders, in other terms the organization should know-who have know-how knowledge. The literature review demonstrated that know-who is essential in organizations, for instance, Kamara et al [17] stated, it is knowledge regarding people with the skills for a specific task, and knowledge of the abilities of suppliers and subcontractors. Also, it is regarding "projects and the people who worked on them or CVs for staff that indicate their special knowledge" (Sun and Howard [18]). The coordinator of national group for protecting Libyan architectural heritage mentioned that knowledge regarding who can or has the ability to diagnose the defects in HBs, identify the right remedies or understand the restoration processes in HBs, is essential knowledge in responsible HB conservation organizations. The insufficiency of know-who knowledge aspects as observed by the author in the MHCB can be attributed to the lack of a data base that includes CVs and details of employees and specialists. Regarding an expertise/skills database, Bishop [19] stated that it is "used to source individuals, encouraging communication".

\section{Conclusions}

The findings presented that a high rate of technical staff left the MHCB between 1986 and 2010. This situation caused a knowledge gap, damage to accumulated knowledge and impacted the performance of the MHCB in terms of repetition of mistakes in repairing HBs. Also, there is the cost of the time and money for rehabilitating technical staff and dealing with external consultancy offices. In the field of $\mathrm{HB}$ conservation, staff leaving is an irreparable loss. This is because the number of specialists is limited, particularly in Libya.

The significant hidden threat to Libyan HBs is most of departing staff will not use their knowledge in the field of HBs conservation. The chance for departing technical staff to get a job in the same field is very few and the opportunity of specialist transition from other organization to MHCB is very few because this institution is unique in Tripoli. In brief, disagreement between some employees and their heads and limited motivation policies in the MHCB combined with unhealthy and dangerous workplaces in old buildings contributing to a significant number of technical staff leaving. However, knowledge management (KM) efforts can help recover some intellectual capital in the MHCB through managing employees and documents' knowledge in particular: Providing appropriate staff motivation policies goals to share/capture knowledge and aid staff retention, providing sufficient information technology that contributes with capturing and sharing knowledge in written or digital form and, establishing database that include information about local experts in the field of HBs conservation. Finally, dealing with external sources of knowledge that include individuals who left the MHCB or retired after significant years of practical experience for developing juniors' knowledge through organising formal/informal events for transferring and exchanging knowledge.

\section{REFERENCES}

[1] Tsoukas, H. (1996) 'The firm as a distributed knowledge system: a constructionist approach', Strategic Management Journal, 17(Winter Special Issue), pp. 1-25.

[2] Rowley, J. (2001) 'Knowledge management in pursuit of learning: the Learning with Knowledge Cycle', Journal of Information Science 27 (4), pp. 227-237.

[3] Consortium, E. (2007) Notes on the conservation restoration of architecture (buildings, monuments and sites).

[4] Feilden, B. (1982) Conservation of Historic buildings. Oxford: Butterworth.

[5] Egbu, C., S. Hari, S. Renukappa (2005) 'Knowledge management for sustainable competitiveness in small and medium surveying practices', Structural Survey, 23(1), pp. 7 $-21$

[6] Sheehan, T., D. Poole, I. Lyttle and C. Egbu (2005) 'Strategies and Business Case for Knowledge Management', in C. Anumba, C. Egbue and P. Carrillo (ed.) Knowledge management in Construction. Oxford: Blackwell Puplishing Ltd, pp. 50-64.

[7] Macintosh, A. (1999) Knowledge management Available at: http://www.aiai.ed.ac.uk/ alm/kamlnks.html\#approach (Accessed: 9/2/2010).

[8] Beijerse, R.P.u. (1999) 'Questions in Knowledge Management: Defining and Conceptualizing a Phenomenon', Journal of Knowledge Management, 3(2), pp. 94 -109.

[9] Rowley, J. (2000) 'From learning organisation to knowledge entrepreneur', Journal of Knowledge Management, 4(1), pp. $7-15$.

[10] Murthy, G., S. Panchal (2011) A presentation oncomprehensive project on knowledge management. Available at:http://www.scribd.com/doc/74667358/8/the-cor e-components-of-km\#page=35 (Accessed: 28/12/2011).

[11] Vector, S. (2008) Knowledge Management Available at: http ://www.vectorstudy.com/management topics/knowledge m anagement.htm (Accessed: 25/1/2011).

[12] Brandon et al (1995) Integrated Construction Information. London: E\&FN Spon.

[13] Tarhuni, S. (2013) The Management of Knowledge in a Historic Building Conservation Organisation in Tripoli, Libya. Ph.D thesis. University of Newcastle upon Tyne.

[14] Bishop, J. (2009) Managing Technical Knowledge to 
Enhance Organisational Best Practice. Loughborough University [Online]. Available at:http://www.lboro.ac.uk/cic e/people/alumni.html (Accessed: 29/07/2010).

[15] Rowley, J. (2001) 'Knowledge management in pursuit of learning: the Learning with Knowledge Cycle', Journal of Information Science 27 (4), pp. 227-237.

[16] Dann, N., S.Wood (2004) "Tensions and omissions in maintenance management advice for historic buildings', Structural Survey, 22(3), pp. 138 - 147.
[17] Kamara, J., C. Anumba, P. Carrillo (2002b) 'Knowledge management in the architecture, engineering and construction industry', Construction Innovation 2(1), pp. 53-67

[18] Sun, M., R. Howard. (2004) Understanding I.T in Construction. London: Spon Press.

[19] Bishop, J. (2009) Managing Technical Knowledge to Enhance Organisational Best Practice. Loughborough University [Online]. Available at:http://www.lboro.ac.uk/cic e/people/alumni.html (Accessed: 29/07/2010). 